\title{
La exposición breve, concisa y concreta de los conceptos usados en todas las ciencias: el Diccionario universal de la lengua castellana, ciencias y artes (1875-1881) dirigido por Nicolás M. Serrano*
}

\author{
M. ' ÁNGELES GARCÍA ARANDA \\ Universidad Complutense de Madrid
}

\section{INTRODUCCIÓN}

La lectura de la bibliografía española especializada en el siglo XIX ${ }^{1}$ muestra que esta centuria «es el siglo de las grandes realizaciones individuales y colectivas, baste recordar nombres como los de José Caballero, Ramón Campuzano, Rufino José Cuervo, Joaquín Domínguez, E. Marty Caballero, Pedro Felipe Monlau, José Ruiz León o Vicente Salvá [podríamos añadir a González Arnao, Pla y Torres, Núñez de Taboada, la editorial Gaspar y Roig, José René Masson, Juan Peñalver, Adolfo de Castro...], la aparición de los primeros diccionarios enciclopédicos y enciclopedias, y, por supuesto, de la actividad académica, que va marcando la pauta de lo que deben ser las recopilaciones generales del léxico» (Alvar Ezquerra 1993: 216).

Ahora bien, mientras que algunos de estos diccionarios han sido estudiados minuciosamente y han ocupado el tiempo de muchos especialistas, otros, en cambio, apenas han sido tenidos en cuenta de manera general; es lo que ocurre, entre otros, con los diccionarios enciclopédicos ${ }^{2}$, lo que llama más la atención si cabe, al alcanzar, precisamente en el

* Este trabajo se enmarca dentro del Proyecto de Investigación Creación y desarrollo de la Biblioteca Virtual de la Filología Española (FFI2011-24107), dirigido por Manuel Alvar Ezquerra.

${ }^{1}$ Me refiero, sobre todo, a los textos generales sobre Lexicografía académica y no académica del siglo XIX, a saber, Seco (2003 [1987]), Alvar Ezquerra (1993), Azorín Fernández (2000a y 2000b), Álvarez de Miranda (2000 y 2007), Ruhstaller (2003), Anglada y Bargalló (1992), Martínez Marín (2000) y García Platero (2003). A estos habría que sumar los estudios sobre lexicografía plurilingüe con el español de la que se han ocupado autores como San Vicente (2010), Cazorla Vivas (2004 y 2010), Marello (1989), Bruña Cuevas (2008), Arce (1988), de Martínez Egido (2008) o de Alvar Ezquerra (2010).

${ }^{2}$ Entre los diccionarios enciclopédicos del siglo XIX destacan el Diccionario castellano de Núñez de Taboada (1825), el Panléxico de Peñalver (1842), el Diccionario de la lengua castellana con las correspondencias catalana y latina de Pedro Labernia (1844), el Nuevo Diccionario de la lengua castellana de Vicente Salvá (1846), el Diccionario nacional de Ramón Joaquín Domínguez (1846-1847), el Diccionario general de José Caballero y Cipriano Arnedo (1849), la Enciclopedia Moderna. Diccionario universal de literatura, ciencias, artes, agricultura, industria y comercio de Francisco de Paula Mellado (1851-1855), el Gran diccionario de la lengua castellana de Adolfo de Castro (1852), el Diccionario enciclopédico de la lengua española de Eduardo Chao (editorial Gaspar y Roig, 1853), el Nuevo Diccionario de la lengua castellana de la Sociedad Literaria (1853), el Novísimo Diccionario de la lengua castellana de Ramón Campuzano (1857), El diccionario general abreviado de la lengua castellana de Lorenzo Campano (1877),

M. á ÁNGElES GarCía ARANDA, «La exposición breve, concisa y concreta de los conceptos usados en todas las ciencias: el Diccionario

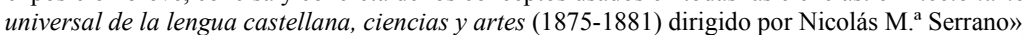
Revista de Lexicografia, XX (2014), pp. 35-56 Fecha de presentación: 21/07/2014 Fecha de aceptación: 12/03/2015 
siglo XIX, «el momento álgido de esta nueva corriente surgida en paralelo a la Academia con nombres como Núñez de Taboada, Pla y Torres, Peñalver, Labernia, Eduardo Chao, Salvá, Adolfo de Casto o Ramón Joaquín Domínguez» (Anaya Revuelta 1999-2000: 9).

El origen ${ }^{3}$ de este movimiento lexicográfico estuvo presidido, como señala Azorín, por intereses marcadamente comerciales, lo que vendría a explicar, en parte, el oportunismo y la escasa calidad de algunos de sus productos [piénsese, por ejemplo, en Peñalver, Núñez de Taboada, Vicente Salvá, Ramón Joaquín Domínguez, Eduardo Chao o Montaner y Simón]. De todos modos, esta circunstancia implícita, por otra parte, en la producción de diccionarios - no llegó a impedir que de este conjunto surgieran obras de indudable mérito. Pero, lo más importante del caso fue la instauración, por primera vez en España, de un incipiente pluralismo en la producción de diccionarios que, finalmente, traería como consecuencia el ensayo de nuevas formas de concebir el diccionario de la lengua (1994-1995: 12).

Pues bien, pese a la difusión de los diccionarios enciclopédicos desde el siglo XIX a la actualidad $^{4}$ «no deja de resultar llamativo el hecho de que en muy pocas ocasiones los investigadores se hayan detenido en su estudio: probablemente, por entender que cae fuera de los límites de nuestra disciplina o por no considerar digno de interés el 'espurio' resultado fruto de una 'lamentable' confusión entre lengua y realidad» (Hernández, 1994: 61). Para tratar de poner fin a la situación que describía el profesor Hernández, y para mostrar la labor lexicográfica más allá de la Academia, este artículo está dedicado a uno de los diccionarios enciclopédicos del siglo XIX: el Diccionario universal de la lengua castellana, ciencias y artes. Enciclopedia de los conocimientos humanos; comprende lengua y gramática castellanas, retórica y poética, crítica, literatura, bellas artes, paleografia, diplomática, heráldica, numismática, lingüistica, mitología, biografía, geografia, matemáticas, ciencias exactas y fisico-naturales, teología, filosofía, religión, culto y liturgia, derecho natural, romano, civil español, político-administrativo, mercantil, penal, canónico, economía, legislación comparada, medicina, industria, comercio, agricultura, política, milicia, pedagogía, educación y bibliografía, dieciséis volúmenes (13 volúmenes, más dos de apéndices y uno de láminas) publicados entre 1875 y 1882 por los hermanos Astort bajo la dirección de Nicolás María Serrano 5 .

Se trata de un repertorio que, tal y como consta en el prólogo, tiene como propósito «poner en manos de todos una obra que explique y defina el sentido de aquellas frases científico-artísticas que son hoy patrimonio universal de las generaciones que viven

el Diccionario enciclopédico Hispano-Americano de Montaner y Simón (1887-1889), el Campano Ilustrado. Diccionario castellano enciclopédico de Manuel González de la Rosa (1891). La mayoría de los textos no académicos, surgidos por el interés de editores franceses, se caracterizan por su deuda con la Academia.

${ }^{3}$ El origen se remonta a Francia, cuyo editores «descubrieron las posibilidades que les brindaba el mercado de las recién emancipadas colonias españolas de América - roto el comercio de ellas con España-, así como la inestimable colaboración de la propia metrópoli al suministrarles suficiente número de intelectuales exiliados útiles para desempeñar la necesaria tarea redactora» (Seco 2003 [1987]: 261).

${ }^{4}$ Piénsese en el Diccionario Enciclopédico Ilustrado de VOX (1995), en el Diccionario Enciclopédico Espasa, 2 vols., Espasa Calpe, en el Gran Diccionario Enciclopédico Ilustrado, Grijalbo (1997) o en el Pequeño Larousse Ilustrado, Larousse (1998), por poner solo algunos ejemplos.

${ }^{5}$ Utilizo el ejemplar que se encuentra en la Biblioteca Histórica Marqués de Valdecilla de la Universidad Complutense de Madrid con signatura BH FOA 6872. 
más inducidas a una extensa cultura que a meditada y profunda investigación en señaladas ciencias» (p. VII).

\section{Nicolás M. ${ }^{a}$ SerRano DíEz (DiRECTOR) Y El RESTO DE COLABORADORES}

En la portada del Diccionario universal queda constancia de que los propietarios de la obra son los hermanos Astort, quienes acometieron la empresa de su edición y publicación, y que esta se compuso bajo la dirección de Nicolás Serrano y «con la colaboración de reputados y distinguidos escritores».

Nicolás Serrano (1841-1899) —abogado, profesor de Derecho en la Universidad Central y en la Universidad de la Habana y diputado a Cortes por Jaruco (Cuba)- fue un aficionado, sin experiencia previa en el oficio, si bien su vida y su obra parecen indicar que fue un hombre formado, con inquietudes en diferentes ámbitos de la vida; así, es autor de El Dios de Suñer y Capdevila (1869), de La Religión o el ídolo del racionalismo (1870), de Elementos de Filosofia del Derecho (1872), de una Historia universal (1874, 6 volúmenes), de un Tratado completo de agricultura moderna (1875), de Anales de la Guerra civil (1875, en colaboración con Melchor Pardo), de Memoria sobre el estado social, político y económico de la isla de Cuba (1892) o de Situación económica de la isla de Cuba al advenimiento del ministerio Cánovas en enero de 1884, entre otras. Además, fue director de La Correspondencia universal (1870), de La Propaganda católica y fundador de La Paz de Cuba y de El Criterio de la Nación.

El resto de colaboradores (entre los que hay españoles, chilenos, mejicanos, argentinos, estadounidenses o peruanos, historiadores, escritores, juristas, políticos, militares, especialistas en Literatura, en Paremiología, en Retórica, en Filosofía, en Teología, en Geografía...)6 del Diccionario universal figura en una lista que precede al prólogo, si bien el Conde de la Viñaza (1893: 1600-1601) sospecha que es posible que «algunos de los que se dan como colaboradores trabajasen poco o nada en la obra, y otros cuyos nombres no constan tomasen en ella gran parte». Lo que sí parece claro es que el método de trabajo, la redacción en equipo, fue otra de las novedades que trajo la Lexicografía del siglo XIX7, la tercera vía 8 que «recoge las ventajas del redactor único y de la labor colectiva, a la par que elude los inconvenientes de uno y otra» (Seco 2003 [1987]: 279).

${ }^{6}$ Entre los muchos colaboradores que cita Nicolás Serrano se encuentran Acosta (D. Cecilio), en Caracas; Almazán (D. Fernando), Sigüenza; Amador de los Ríos (D. José); Araujo (D. Manuel), Brasil; Arenal (Doña Concepción); Barros (D. Diego), Chile; Boix (D. Vicente), Valencia; Bonnetty (Abate), París; Campoamor (D. Ramón); Cánovas del Castillo (D. Antonio); Cevallos (D. Pedro), Guayaquil; Crespo (D. Manuel), Mondoñedo; Díaz Jurado (D. Rafael), Toledo; Fernán Caballero; Ferrer de Couto, Estados-Unidos; García Sanz (D. Faustino), Soria; González Peña (D. Ildefonso), Calahorra; González Sistiaga (D. José), Ciudad-Rodrigo; Hartzenbusch (D. Juan Eugenio; Lafuente (D. José J. de), Bilbao; Machado (D. Silvestre), Tenerife; Minoracid (D. Galo), Segorbe; Orberá (I. S. D. M.), Santiago de Cuba; Plá (D. Antonio), Lugo; Ricafort (D. Enrique); Torres Villanueva (D. José); Zamora y Caballero (D. Eduardo) o Zorrilla (D. José), entre otros muchos.

${ }^{7}$ Seco (2003 [1987]: 279) afirma que «el sistema, en su forma más tímida, aparece en el Diccionario general de 1849 , cuyos autores son José Caballero y Cipriano de Arnedo, y se enriquece con las ediciones posteriores de la misma obra, en las cuales José Caballero aparece como director y la elaboración corresponde a 'una sociedad de literatos' [...]. Donde se lleva a una forma más elaborada este sistema es en el Diccionario enciclopédico de Gaspar y Roig, redactado por una 'sociedad de personas especiales en las letras, las 


\section{LA OBRA: UN DICCIONARIO ENCICLOPÉDICO}

Aunque no es objeto de este trabajo contribuir a la diferenciación, muchas veces debatida, entre diccionario de lengua, enciclopedia y diccionario enciclopédico ${ }^{9}$, no se puede obviar la caracterización que del Diccionario universal enciclopédico ${ }^{10}$ hace Nicolás Serrano en el prólogo.

Serrano afirma que su obra se diferencia claramente de un diccionario de lengua y de una enciclopedia; del primero porque tiene «por objeto mantener incólume la pureza de la lengua castellana [se refiere al diccionario de la Real Academia Española]», y de la segunda porque «abarca la exposición y sentido del saber humano, obra dificilísima en el estado actual de la ciencia, intentada sin fruto hasta el presente, y que bien bajo el ideal irrealizable de los mantenedores de la ciencia absoluta, como bajo el modesto plan de filósofos más racionales, no se alcanza a vislumbrar la época en que haya de ser una realidad la Enciclopedia [...]» (p. VII). Dentro del cuerpo del Diccionario universal, amplía estas definiciones, a saber, el diccionario es

el libro, en forma de catálogo, que contiene por orden alfabético todas las voces de una o más lenguas o las pertenecientes a una facultad o ciencia determinada, explicando sus significaciones y acepciones en el mismo idioma, o sus equivalentes en otro. Los diccionarios son los archivos de las lenguas, donde deben ser recogidas y clasificadas todas las palabras de cada una de estas lenguas, para el uso de los pueblos que las hablan [...] (s.v. diccionario).

Por su parte la enciclopedia es definida como

nombre que daban los griegos al encadenamiento de todas las nociones que habían de entrar en la educación de un hombre libre, es decir, del que nada debe ignorar de lo que le concierne.- Ciencia universal, enseñanza de todos los conocimientos humanos. [...] una buena enciclopedia completa es imposible en el estado actual de la ciencia, porque es imposible abarcarlo todo y colocarlo todo en el mejor orden $[\ldots]$ (s. v. enciclopedia).

Por estas razones, la editorial Astort se decanta por un diccionario enciclopédico, esto es, un «ordenado y breve resumen del tecnicismo científico, acompañado del tesoro de la lengua castellana», o, dicho de otra forma, «un término medio entre las Enci-

ciencias y las artes', constituida por doce individuos cuyos nombres se detallan, y revisado por otros nueve, también nombrados, bajo la dirección general de Eduardo Chao».

${ }^{8}$ Para Seco (2003 [1987]: 279), esta tercera vía se suma a otras dos ya existentes, a saber, «la redacción colegiada e impersonal practicada por la Academia y seguida por la Sociedad Literaria, y la redacción unipersonal de Taboada, Labernia, Salvá, Domínguez y Castro - la única practicada hasta entonces en la lexicografía no académica一».

${ }^{9}$ Una muestra de la bibliografía que aborda el problema, desde diferentes perspectivas teóricas y metodológicas, se encuentra en Haensch et alii (1982 y 2004), Schiffrin (1984), Seco (1987), Rey (1988) Lara (1989 y 1990), Forgas (1996), Gutiérrez Cuadrado (1996), Hernández (1997), Anaya (2000a y 2000b), Porto Dapena (2002), Bergenholtz y Tarp (2002), Campos y Pérez Pascual (2003), Geraerts (2003), Hartmann (2003), Van Sterkenburg (2003), Béjoint (2004), Soler i Bou (2006), Fillmore (2003, 2008a y 2008b), Fontenelle (2008), Hanks (2008), Labov (2008).

${ }^{10}$ Otros títulos de repertorios similares son Diccionario nacional (Domínguez), Diccionario general (Caballero y Arnedo), Gran diccionario (Castro), Diccionario enciclopédico (editorial Gaspar y Roig, dirigido por Eduardo Chao), Nuevo diccionario (Sociedad Literaria)... 
clopedias extensas y los Diccionarios conocidos hasta ahora, con cuyo plan creemos prestar un gran servicio a los amantes de la cultura» (p. X).

Esta definición (diccionario enciclopédico $=$ el tesoro de la lengua castellana + un resumen del tecnicismo científico) no se aleja mucho de otras dadas con posterioridad, en donde el diccionario enciclopédico es caracterizado como «solución híbrida entre el diccionario de lengua y la enciclopedia» (Fernández-Sevilla 1974: 67 y Alvar Ezquerra 1980: 116) ${ }^{11}$, como «obra, efectivamente, heterogénea, que participa de las cualidades de un verdadero diccionario y de una verdadera enciclopedia» (Hernández 1997:160), o como una «obra de carácter polivalente, que participa simultáneamente de las características de los diccionarios y de las enciclopedias» (Anaya Revuelta 1999-2000: 15) ${ }^{12}$.

Así lo entiende también Nicolás Serrano, para quien

Son objeto y fin propios del Diccionario universal y enciclopédico, definir aquellos conceptos usados entre los pueblos, como patrimonio común de los adelantos y progresos que todas las ciencias, y singularmente las físico-naturales, han realizado en los siglos precedentes, y dar nociones breves, precisas y concretas de cada una de ellas, en cuanto basten a satisfacer las más urgentes necesidades que el concierto social exige en la época presente, y la cultura, más universal que profunda, reclama; dando cabida, no ya solamente a la rigurosa y estricta enumeración de las palabras propias de una lengua, sino también a cuantas la novedad y utilidad otorguen carta de introducción (p. VI).

Todo lo cual justificaría la publicación del Diccionario universal, ya que el diccionario de lengua (el de la Academia que debe «evitar las numerosas exigencias del lenguaje técnico» y ocuparse de «su composición, pureza y estructura a través de los siglos») debe completarse -máxime si se trata, como es el caso, del siglo de las invenciones, los avances, los progresos y los adelantos científicos y técnicos- con otros repertorios que contengan todos los tecnicismos científicos, literarios y artísticos, «es el Diccionario el primer libro de un pueblo, é importa sobremanera su respeto y estudio [...] ya que como al presente nunca vivieron los pueblos en tan continuas y fáciles relaciones, merced a los inventos admirables del hombre en la edad moderna» (pp. V-VI).

Por otro lado, el interés del Diccionario universal por proporcionar «nociones breves, precisas y concretas de cada una de las ciencias», por «exponer en forma metódica estas grandiosas conquistas del poderío humano», por «satisfacer las más urgentes

${ }^{11}$ Las definiciones completas son «solución híbrida entre el diccionario de lengua y la enciclopedia, que da cabida simultáneamente al conjunto del léxico, con todas las clases de palabras, y al conjunto de las cosas, con nombres propios e ilustraciones» (Femández-Sevilla 1974: 67) y «es una solución híbrida entre ambas obras, pues en una enciclopedia Los diccionarios enciclopédicos del español actual tendrá cabida tanto el conjunto de las voces de una lengua, como el conjunto de cosas, hechos, lugares y personas propios de una época o cultura, esto es, un diccionario y una enciclopedia en un orden único» (Alvar Ezquerra 1980: 116).

${ }^{12}$ Ello desde un perspectiva tradicional, pues en Lingüística cognitiva «se asume que no es posible establecer una separación tajante y efectiva entre significado lingüistico, es decir, la información que tenemos sobre un elemento, que va a ser relevante para hablar, y el significado extra-lingüístico o enciclopédico, aquello que sabemos sobre algo que con toda seguridad no es necesario para la lengua. Potencialmente, todo lo que sabemos sobre algo puede ser potencialmente relevante en un momento dado y por lo tanto, hay que optar por una visión del significado de enciclopedia más que de diccionario» (IbarretxeAntuñano y Valenzuela 2012). 
necesidades que el concierto social exige en la época presente» (p. VI), por, en definitiva, popularizar los nuevos conocimientos que trajo consigo el siglo XIX, empuja a $\mathrm{Ni}$ colás Serrano a perfilar en su prólogo al destinatario de su obra

Ayer, cuando la vida de los sabios era vida de comunidad, la biblioteca lo suplía todo ventajosamente; hoy, que el individualismo es la consecuencia de funestas negaciones, no hay posición ni clase que no necesiten contar para los fines de su vida con medios y elementos propios. El sabio, el agricultor, el industrial, el comerciante, todos han menester en sus relaciones un libro de enseñanza compendiada y de fácil, ordenada y metódica consulta, para responder a sus dudas y al legítimo deseo de una ilustración bien entendida [...], que deseamos ver consultado en nuestro país, no sólo por la clase ilustrada, sino por el industrial y el obrero, como en obras de igual género consultan los obreros ingleses y americanos, las horas en que el descanso les permite saborear los dulces sentimientos de la religión, de la familia y de la ilustración (p. IX).

\section{EL DICCIONARIO UNIVERSAL O LA EXPOSICIÓN BREVE, CONCISA Y CONCRETA DE LOS CONCEPTOS USADOS EN TODAS LAS CIENCIAS}

Dado que, como se ha señalado, el objeto del Diccionario universal y enciclopédico es exponer de forma breve, concisa y concreta los conceptos usados en todas las ciencias y «satisfacer las más urgentes necesidades que el concierto social exige en la época presente, y la cultura, más universal que profunda, reclama», el repertorio acoge tanto entradas propias de un diccionario de lengua como enciclopédicas, dando cabida a términos científicos y técnicos, topónimos, personajes y hechos históricos, entre otros muchos $^{13}$. En el interior del artículo lexicográfico, la parte más elaborada y cuidada es también la información enciclopédica, información que, aunque aparece en último lugar, ocupa una extensión considerable

En la explicación respectiva de cada una de las palabras, procuraremos seguir, en cuanto es posible, el siguiente y facilísimo método: primeramente, la explicación gramatical; en segundo término, la explicación que convenga a cada palabra en orden o concepto morales; y en tercero, el propio a ciencias físico-naturales, artes y oficios. Nuestro Diccionario contendrá la explicación técnica de la inmensa mayoría de las palabras más usuales, dando a algunas aquella extensión necesaria y conveniente a la propagación de los progresos modernos y teorías más en boga (p. X).

Los artículos lexicográficos del Diccionario universal se estructuran de la siguiente forma: enunciado o lema (que, en ocasiones, son polimórficos: acerdesia o acerdesa // abircuajar, abircuajabe o abircuayabe // abitar o Bitar // abondadura, abondamiento, abondancia // abotagarse o abotargarse // ábsida o ábside...), información gramatical

${ }^{13}$ Como es habitual en los diccionarios enciclopédicos el único criterio de selección utilizado es el acumulativo, de modo que el Diccionario universal y enciclopédico de Nicolás Serrano reúne en sus páginas ciudades de Dinamarca (Aarhus), reyes de Hungría $(A b a)$, aves fabulosas mencionadas en el Corán (Ababil), casas rurales lucenses (Abade), emperadores otomanos (Abdul-Hamid), califas (Abdul-Malik), generales ingleses (sir Abercromby), historiadores escoceses (Tomás Abercromby), ciudades americanas (Santa Fe o Entre-Ríos), insectos (Feburia, Fedropo), alemanas (Fecocourt), japonesas (Fecouri), holandesas (Raamsdonk), árboles de Brasil (Feocarpo), plantas (Ferdinandusa), monedas (Ferdono) o literatos holandeses (Pedro Rabus), por poner solo algunos ejemplos. 
(v., s., adj., part., masculino, femenino, activo, impersonal, recíproco, neutro, pasivo...), marcas (dado el tipo de diccionario de que se trata, terminológicas; hay voces de la agricultura, de la albeitería, de álgebra, de anatomía, de astrología, de ballestería, de cantería, de cetrería, de cirugía, de cocina, de comercio, de escultura, de farmacia, de física, de fortificación, de geología, de gramática, de historia, de heráldica, de iconografía, de jurisprudencia, de literatura, de marina, de matemáticas, de medicina, de milicia, de música, de óptica, de pedagogía, de política, de prosodia, de teología, de volatería o de zoología, entre otras muchas; si bien no faltan otros términos marcados como anticuados, familiares, provinciales, irónicos o metafóricos, esto es, marcas diafásicas, diastráticas y geográficas)

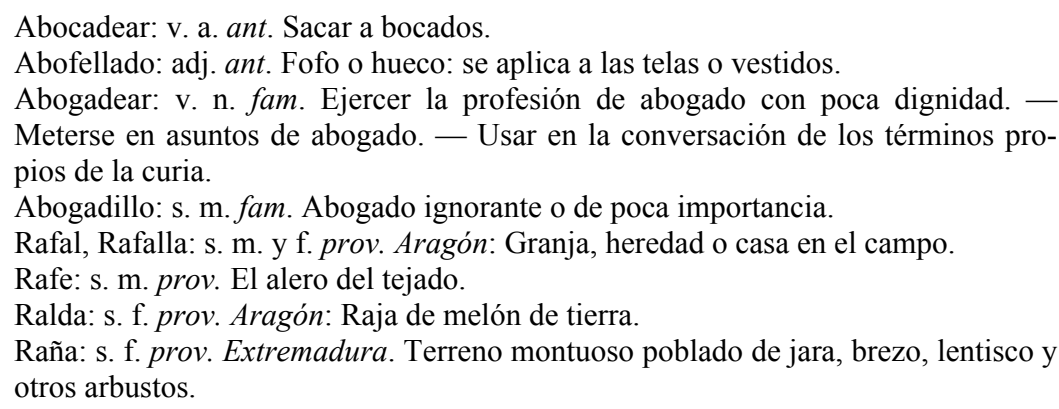

Y, finalmente, la acepción o acepciones de las voces, primero las generales o comunes y, en segundo lugar, las especiales o particulares. Al igual que el Diccionario de la Real Academia Española, a quien Nicolás Serrano cita entre sus fuentes, «en cada artículo van colocadas por este orden las diversas acepciones de los vocablos: primero, las de uso vulgar y corriente, después, las anticuadas, familiares, las figuradas, las provinciales e hispanoamericanas, las de Germanía y, por último, las técnicas» (prólogo del DRAE de 1884, edición a partir de la cual la Real Academia Española incluye unas Reglas o advertencias); el Diccionario universal, entonces, reproduce o adapta la acepción del $D R A E$ y, a continuación, incorpora, en cada caso, la información enciclopédica o las acepciones especializadas:

Abacería: f. El puesto o tienda pública donde se vende aceite, vinagre, pescado, legumbres secas, etc. (DRAE-1869)

Abacerías: s. f. Las tiendas o puestos públicos donde se vende por menor aceite, vinagre, pescado, legumbres secas y otros artículos de ordinario consumo.

No siempre ha podido cualquiera establecer libremente ABACERÍAS. Hubo un tiempo en que algunos se arrogaban este privilegio, y no permitían su ejercicio, sino a los sujetos a quienes lo daban en arriendo; mas don Fernando y doña Isabel, en pragm. de 4 de Diciembre de 1492, y D. Carlos y doña Juana, en 1532 (ley 1 , tít . XXI, lib. V I , Nov. Recop.), prohibieron a todas las personas de cualquier estado y posición, preeminencia y dignidad el poner tales estancos o vedamientos en sus villas, lugares, tierras $u$ otras partes, bajo las penas en que caen por las leyes los que piden y llevan nuevas imposiciones, por ser contrarias a derecho y conciencia, y en gran daño de los súbditos y vecinos.

Más tarde tomaron a su cargo los ayuntamientos la tutela de sus vecinos, y o bien administraron por cuenta del público el surtido de los artículos de primera necesi- 
dad, o bien buscaron asentistas exclusivos que se obligasen a procurarlos y venderlos a tales o tales precios concertados $[\ldots]$.

Abadejo: m. Pescado de dos o tres pies de largo, que se pesca con suma abundancia, especialmente en el banco de Terranova, y se conserva salado.— Pájaro de Europa, de tres a cuatro pulgadas de largo, y muy vistoso por la variedad de sus colores.- Insecto sin alas, de más de una pulgada de largo, negro y con unas rayas trasversales encarnadas. Es el que por otro nombre llaman cantárida. (DRAE-1869)

Abadejo: s. m. Zool. Pez de la familia de los gadóideos, de dos o tres pies de largo, que abunda en el N. de ambos hemisferios, y especialmente en los mares de Escocia y Noruega, y en el banco de Terranova: se conserva salado y curado. - Pájaro europeo de vistosos y variados colores.- Insecto venenoso, sin alas, de más de una pulgada de largo, negro y con rayas trasversales encarnadas: el aceite preparado con él se usa para vejigatorios.

Abadiado: m. ant. ABADíA. Hoy se usa en la corona de Aragón por el territorio de la abadía. (DRAE-1869)

Abadiado: s. m. ant. Abadía. Hoy se usa en la corona de Aragón por el territorio de la abadía.

Acelga: f. Planta hortense cuyas hojas son grandes, anchas, gruesas, lisas, jugosas y acanaladas. La hay de varias especies, que se distinguen por su color más o menos verde. (DRAE-1869)

Acelga: s. f. Planta hortense de hojas grandes, anchas, gruesas, lisas, jugosas y acanaladas. La hay de varias especies, según su color más o menos verde.-Bot. Planta comestible, género de la familia de las atripliceas y de la peutandria diginda, cuyas principales especies pasamos a enumerar.-ACELGA MARÍTIMA, beta marítima: Planta de la familia de los armuelles, indígena, que se cría espontáneamente a orillas del mar, donde sus hojas servían antiguamente, y aun a veces sirven todavía, al mismo objeto de cocina que entre nosotros la ACELGA común, beta, vulgaris; la cual, verosímilmente, no es más que una variedad procedente del cultivo, como lo piensan en la actualidad la mayor parte de los botánicos [...].

Banca: f. Asiento de madera sin respaldo y a modo de una mesilla baja.-El cajón hecho de tablas donde se meten los lavanderos y lavanderas para preservarse de la humedad de las aguas en que lavan la ropa.-Juego que consiste en poner el que lleva el naipe una cantidad de dinero, que también se llama BANCA, y los que ponen contra este, apuntan a las cartas que eligen la cantidad que quieren.- Ant. La mesa de cuatro pies puesta en la plaza ú otros parajes públicos para el despacho de frutas y otras cosas que se venden.- Comercio que principalmente consiste en operaciones de giro, cambio y descuento, en abrir créditos y llevar cuentas corrientes, y en comprar y vender efectos públicos, especialmente por cuentas de otras, percibiendo en recompensa un interés que se llama comisión.- CASA DE BANCA. La de comercio que se dedica a este género de operaciones, que también se llaman de BANCA, y BANQUEROS los jefes de aquellas. (DRAE-1869)

Banca: s. f. Asiento de madera sin respaldo y a modo de una mesilla baja.-El cajón hecho de tablas donde se meten los lavanderos y lavanderas para preservarse de la humedad de las aguas en que lavan la ropa.- Juego, que también se llama del monte, y consiste en sacar de la baraja el que hace de banquero cuatro naipes, dos por abajo, a los que dan el nombre de albur, y dos por arriba, que dicen gallo, entendiéndose que se apunta a los primeros antes de salir los segundos: ejecutado esto, vuelve el banquero las cartas y las va desuniendo una por una, hasta sacar la 
igual de alguna de las que juegan, en cuyo caso ésta ganará.- Denominase también así el fondo o dinero puesto y abonado por el que talla, tanto en éste como en otros juegos que le son parecidos.- Ant. La mesa de cuatro pies puesta en la plaza ú otros parajes públicos para el despacho de frutas.-Com. Se da el nombre genérico de comercios de BANCA a esa industria que toma a su cargo, mediante una cierta retribución, trasmitir capitales a los que los han menester para sus operaciones y trabajos. Puede decirse que los banqueros, o sea los que se dedican al comercio de BANCA, son los agentes intermediarios entre el trabajador que reclama el capital y los poseedores de los capitales mismos, que no quieren o no saben hacerlos producir, y a quienes se designa con el nombre de capitalistas. No se limitan, por cierto, a ésta sola las operaciones de los banqueros; pero como es la principal de ellas, nos limitamos a esta definición, reservándonos darle en los párrafos que siguen el desenvolvimiento necesario [...].

Raigal: adj. Lo que toca a la raíz. Entre los que tratan en madera se llama así el extremo del madero que corresponde a la raíz del árbol. (DRAE-1869)

Raigal: adj. Lo que toca a la raíz. Entre los que tratan en madera se llama así el extremo del madero que corresponde a la raíz del árbol.

Raigambre: f. El conjunto de raíces que esparcen por la tierra uno o muchos árboles o plantas, unidas o trabadas entre sí. (DRAE-1869)

Raigambre: s. f. El conjunto de raíces que esparcen por la tierra uno o muchos árboles o plantas, unidas o trabadas entre sí.

Ramificación: f. Extensión, división o esparcimiento de alguna cosa. || Anat. La división y extensión de las venas, arterias o nervios que como ramas nacen de un mismo principio o tronco. (DRAE-1869)

Ramificación: s. f. Extensión, división o esparcimiento de alguna cosa.- Serie de puntos de contacto que tienen unos objetos con otros.- Anat. Nombre dado a las divisiones de los ramos de las arterias, venas o nervios.-Bot. y Zool. Nombre dado a la reunión de las divisiones de un órgano cualquiera en varias ramas o ramos, y también a las mismas divisiones.

Raquitis: Med. Vicio constitucional, frecuentemente hereditario, que consiste en una perturbación de la nutrición de todos los tejidos, y que, sobreviniendo en la infancia, se manifiesta principalmente en el sistema óseo por la distensión del cráneo, la corvadura del RAQUIS y la deformación de varios huesos largos, con entumecimiento de las articulaciones. (DRAE-1869)

Raquitis: s. f. Med. Enfermedad en la que la cabeza, el espinazo, las costillas, la tibia y otros huesos, experimentan una deformidad notable, y que está caracterizada por un aumento de volumen del cráneo, hinchazón de las articulaciones, aplanamiento de las costillas, encorvadura viciosa de la columna vertebral sobre las costillas, hacia atrás o adelante, encorvamiento de los huesos largos, elevación del vientre y enflaquecimiento general.

Lo ordinario es que se presente esta enfermedad en la infancia, pero muy raras veces en la edad adulta. Sin embargo, Morand cita un ejemplo de este último caso [...].

Este interés por las acepciones técnicas o científicas causa que, en ocasiones, Nicolás Serrano altere el orden de las acepciones del DRAE para colocar al final del artículo lexicográfico - incluso después de la fraseología — la información especializada, marcando así terminológicamente una acepción que es general, o, incluso, separando en artículos lexicográficos diferentes lo que en otros casos son subentradas dentro del 
artículo, y es como el propósito del Diccionario universal es «dar nociones breves, precisas y concretas de cada una de las ciencias (singularmente las físico-naturales)» ayuda mucho, sin duda alguna, su marcación

Rábano: m. Planta que echa las hojas anchas, largas y caídas sobre la tierra, de color verde muy subido, ásperas al tacto y pendientes de un tallo de altura de una vara. La flor es pequeña y abierta en cuatro hojas amarillas, en cuyo hueco echa una simiente pequeña y redonda. La raíz, que tiene el mismo nombre, es blanca mezclada por lo común con rojo muy encendido, y a veces toda ella de este color, larga y que remata en punta y tiene a trechos pendientes unas hebrillas como vello. $\|$ RABANILlO agrio, etc. \| RÁBANOS Y QUESO TRAEN LA CORTE EN PESO. ref. con que se significa que se deben atender las cosas más mínimas en cualquier materia para el logro de las mayores o importantes || TOMAR EL RÁBANO POR LAS HOJAS. fr. met. Invertir el orden, método o colocación de las cosas, haciendo las primeras últimas o al contrario. (DRAE-1869).

Rábano: s. m. (V. Rabanillo en su primera acepción).- TOMAR EL RÁBANO POR LAS HOJAS: fr. Invertir el orden, método o colocación de las cosas, haciendo las primeras últimas o al contrario.- Atribuir a una expresión diverso sentido del que ha querido darle el que la dijo.- RÁBANOS Y QUESO TRAEN LA CORTE EN PESO. ref. que significa que se deben atender las cosas más mínimas en cualquier materia para el logro de las mayores o importantes.- CUANDO PASAN RÁBANO COMPRARLOS: aconseja que se dejen perder las ocasiones.-Bot. Género de plantas de la familia de las crucíferas ortoplóceas, cuyas especies son hierbas espontáneas que crecen en la Europa central y meridional y en el Asia; tienen la raíz fusiforme, las hojas polimorfas y echan las flores amarillas o blancas formando grupos.- RÁBANO CULTIVADO: Especie de plantas del género rábano, que es anual y se cultiva en toda Europa, especialmente en España. Su raíz es carnosa y varía mucho en dimensiones, forma y color; la fécula que contiene es muy ligera y estimulante, y sus semillas no sirven más que para la siembra, aunque el aceite que se puede extraer de ellas sería muy bueno como condimento.

Rabel: m. Instrumento músico pastoril. Es pequeño, de hechura como la del laúd. Compónese de tres cuerdas solas, que se tocan con arco, y tienen un sonido muy alto y agudo. || Se da también este nombre a otro instrumento que consiste en una caña y un bordón, entre los cuales se coloca una vejiga llena de aire. Se hace sonar la cuerda con un arco de cerdas, y sirve para juguete de los niños. || festivo y fam. El trasero, especialmente hablando con los muchachos (DRAE-1869).

Rabel: s. m. fam. El trasero, especialmente hablando con los muchachos. - Farm. Agua de RABel (V. AGUA).- Mús. Instrumento músico pastoril. Es pequeño, de hechura como la del laúd. Compónese de tres cuerdas solas, que se tocan con arco, y tienen un sonido muy alto y agudo.- Se da también este nombre a otro instrumento que consiste en una caña y un bordón, entre los cuales se coloca una vejiga llena de aire. Se hace sonar la cuerda con un arco de cerdas, y sirve para juguete de los niños.

Rabia: f. Enfermedad que priva del sentido y causa furor, melancolía y otros extraños accidentes. Es mortal y contagiosa, comunicándose las más veces por la mordedura del animal dañado. Es propia del perro, aunque otros muchos están sujetos a padecerla. $\|$ met. Ira, enojo, enfado grande. $\|$ Se usa como expresión de admiración para más explicar y ponderar alguna cosa. \| DE RABIA MATÓ LA PERRA. loc. con que se da a entender que el que no puede satisfacerse del que le agravió, se venga en lo primero que encuentra. || ESTAR TOCADO DEL MAL DE LA RABIA. fr. fam. 
Estar dominado o poseído de alguna pasión. \| TOMAR RABIA. V. CÓLERA. (DRAE1869).

Rabia: s. f. met. Ira, enojo, enfado grande. Se usa como expresión de admiración para más explicar y ponderar alguna cosa.- Dolor, pena, desesperación.- - $\| \mathrm{DE}$ RABIA MATÓ LA PERRA. fr. Da a entender que el que no puede satisfacerse del que le agravió, se venga en lo primero que encuentra.- ESTAR TOCADO DEL MAL DE LA RABIA: Estar dominado o poseído de alguna pasión.- TOMAR RABIA: (V. CÓLERA).

- Med.. Enfermedad particular a los animales del género perro y gato, y contagiosa para el hombre lo mismo que para todos los animales, caracterizada principalmente por una sensación de ardor y de construcción en el cuello y en el pecho, una viva exaltación de los órganos de los sentidos, el horror a los líquidos, algunos espasmos convulsivos, algunos ataques de furor, y en fin, una muerte pronta. Si bien es cierto que muchos profesores se han declarado por la admisión de un virus o de un principio específico contagioso de la rabia, no lo es menos que otros le han puesto en duda, y que algunos lo han negado rotundamente. Bosquillon creía que la rabia dependía en todos los casos del miedo o de una imaginación herida de cierta manera; a decir verdad no es nueva esta idea, pues estaba ya hábilmente combatida por varios médicos, quienes hicieron observar que algunos caballos, asnos y mulos, quipus non est intellectus, mueren rabiosos, y que un niño de pecho murió de esta enfermedad, al paso que se salvaron, o no la contrajeron, otros que eran sumamente tímidos $[\ldots]$.

En otras ocasiones, en cambio, elimina cualquier información que no sea enciclopédica y deja solo la acepción con marca de especialidad

Abeja: f. Insecto con alas, de tres a cuatro línea de largo, que con muchos individuos de su especie vive siempre en laboriosa sociedad, habitando en su estado silvestre los huecos de los árboles o de las peñas, y en el doméstico las colmenas que el hombre le prepara a fina de aprovecharse de la cera con que fabrica sus panales y de la miel que deposita en ellos, extraída de las flores. I MACHIEGA Y MAESA. La hembra de los zánganos, y la madre de las abejas que fabrican la miel y la cera. Es única en cada colmena, y basta para más de mil machos. || MAESTRA. MAESA. || ABEJA Y OVEJA, Y PARTE EN LA IGREJA, DESEA A SU HIJO LA VIEJA. ref. que advierte que la carrera eclesiástica, el ganado lanar y los colmenares proporcionan comodidades y riquezas. (DRAE-1869).

Abeja: Zool. Es un insecto himenóptero, que entra en el número de los que vuelan con ayuda de cuatro alas desnudas, membranosas, desiguales y venenosas. El sabio Latreille colocó este insecto en la tribu de los melíferos o apiarios, segundo de la familia que ha establecido con el nombre de antofilas (amigas de las flores). En efecto, entre las preciosas y perfumadas corolas que matizan nuestros bosques, jardines y praderas, es donde gustan vivir los himenópteros a los cuales fue concedida la singular industria de extraer del polen los materiales de la habitación cuajada de néctar que tan bien sabe utilizar el hombre.

La naturaleza, que dividió casi todas las especies animales en dos suertes de individuos, machos y hembras, o que lejos de privar de sexo a estas especies, concedió dos a algunas, parece que se propuso quebrantar las reglas que presiden al resto de la organización específica, para singularizar las antofilas melíferas, y unir a la industria, tan admirable en ellas, un nuevo elemento de sociabilidad; pero de una sociabilidad bien extraña, puesto que se funda en la desigualdad de las condiciones: decimos esto, porque la anatomía ha reconocido en estos seres hasta tres castas diferentes, y tal vez cuatro. 
La sociedad de las ABEJAS ofrece: $1^{\mathrm{a}}$ neutras, divididas en dos clases, obreras y nutrices; $2^{\mathrm{a}}$ machos; $3^{\mathrm{a}}$ una sola hembra para cada república de quince a treinta mil individuos, en cuya cantidad hay en lo sumo de seiscientos a mil machos.

Las obreras (ó llámense trabajadoras), y las hembras están provistas de aguijones, de que carecen los machos, cuyo tamaño excede al de las primeras, sin igualar al de las segundas: por otra parte, tienen la cabeza más redondeada, los ojos oblongos y monos salientes. Inhábiles para el trabajo y sin utilidad en una república donde sólo se tolera una hembra destinada a la propagación, su suerte es digna de lástima, pues se hallan sin defensa entre una multitud capaz de exterminar los miembros inútiles del cuerpo social. Encuentra la hembra a uno de estos machos, se une a él en las regiones etéreas, encontrándose así fecundada para un año, y aun para toda la vida, si hemos de dar crédito a ciertos observadores; en cuanto al macho, no alcanza la dicha de conocer su progenitura, pues halla la muerte cuando sólo apetecía y buscaba el goce $[\ldots]$.

El afán por recopilar voces y «ordenar metódicamente un sumario de los conocimientos humanos» (p. v) empuja, de nuevo, a los hermanos Astort a incluir en la nomenclatura del Diccionario universal numerosos neologismos (marcados con $N$ ) y americanismos (marcados con $\mathrm{Am}$ ) que en 1875 todavía no habían entrado en el repertorio de la Real Academia Española - referente que no sorprende habida cuenta de la influencia que tuvo la producción lexicográfica de la Academia desde el siglo XVIII-.

Rastrilla: s. f. dim. de Rastra.

Rastrillada: s. f. Todo lo que se recoge o barre de una vez con el rastrillo o rastro.

Rastrillado, da: part. pas. De Rastrillas y Rastrillarse.

Rastrillador, ra: s. El que rastrilla. Se usa también como adjetivo.

(N) Rastrilladura: s. f. Acción o efecto de rastrillar.

(N) Rastrillamiento: s. m. (V. Rastrilladura).

(N) Rastrillante: part. a. de Rastrillar. Que rastrilla.

Rastrillar: v. a. Limpiar el lino o cáñamo, despojándolo de la arista y estopa por medio del rastrillo. -Recoger la parva en las eras con el instrumento que denominan rastro. - Pasar el rastrillo o la grada por un campo sembrado. Se usa también como recíproco.

(N) Rastrillazo: s. m. aum. de Rastrillo. -Golpe dado con el rastrillo

(N) Rastrilleo: s. m. El acto de rastrillas. - Su efecto.

(N) Rastrillito: s. m. dim. de Rastrillo.

Rasurado, da: part. pas. de Rasurar y Rasurarse.

Rasurador, ra: s. El que rasura. Se usa también como adjetivo.

Rasurar: v. a. Rapar, quitar o cortar la barba o el cabello. Se usa también como pronominal

(Am.) Caá: s. f. Bot.. Nombre que se da en el Paraguay a su famosa hierba, que reemplaza al te, y de la que se hace un gran consume en muchas provincias de la América Meridional [...].

(Am.) Fedropo: s. m. Zool. Género de insectos coleópteros tetrámeros, de la familia de los curculiónidos gouatóceros, compuesto de dos especies, una de Cayena y otra del Brasil.

(Am.) Feocarpo: s. m. Bot. Árbol del Brasil, cuyos frutos son de un color moreno.

La editorial Astort y Nicolás Serrano entienden que una obra de estas características, con la exposición breve, concisa y concreta de los conceptos usados en todas las ciencias, es el «medio más eficaz de propagar los conocimientos humanos y de hacer- 
los descender a aquellas clases de la sociedad que por largos siglos han permanecido extrañas a los progresos del entendimiento humano» (s.v. enciclopedia); el Diccionario universal de la lengua castellana, ciencias y artes ayuda, pues, a esta propagación, la «única que puede poner remedio a ese desnivel de clases de que se quejan hoy, y que es causa frecuente de perturbaciones en nuestra sociedad» (s.v. enciclopedia). Para conseguirlo, no obstante, es necesario manejar muchas fuentes, utilizar en su elaboración numerosas obras de contenidos muy diversos.

\section{LAS FUENTES DEL DICCIONARIO UNIVERSAL}

El Diccionario universal dirigido por Nicolás Serrano no es original; antes de su publicación otros muchos, como hemos visto anteriormente, habían aparecido en España y, sobre todo, en Francia. Pero este hecho no es ocultado por Serrano, quien reconoce en el prólogo de la obra las fuentes (sobre todo extranjeras) que le han servido de inspiración

Para llevar a término feliz esta empresa, hemos tenido a la vista numerosos Diccionarios, escogidos de entre los más selectos extranjeros, debiendo hacer mención de los publicados en Francia por Migne, en Inglaterra por Smith, verdadero tesoro de geografía y antigüedades, y en Alemania por Brochaus. De los preciados trabajos llevados a cabo en España, hemos recibido poderoso auxilio, si bien no tanto como nuestro deseo hubiera querido, para tributarles este homenaje de admiración.

Fuerza es declarar, con harto sentimiento, que los siglos anteriores nos han ofrecido mayores datos que el siglo XIX, en cuanto se refiere a nuestra patria, y que la más difícil empresa ha sido todo lo referente a nuestra nación; ¡ ¡sto, aun dado en el siglo actual tanto afán periodístico, tan enemigo de ser acusado de rémora del libro! (p. X)

Parece que Nicolás Serrano se refiere, respectivamente, a las obras de las editoriales del abate Jacques-Paul Migne (enumera los siguientes: Diccionario de geografía sagrada, Manuscritos, Tradiciones pontificias, Arqueología, Apócrifos, Disciplina eclesiástica, Economía política, Historia y Geografia, Zoología, Paleografia, Numismática, Botánica, Astronomía, Indulgencias, Antifilosofismo, Supersticiones, Liturgia, Apología, Música, Cosmogonía, Paleontología, Concilios, Peregrinaciones, Órdenes religiosas, Geología y Cronología), de William Robertson Smith (editor de la Encyclopaedia Britannica y de La religión de los semitas, texto clave en el estudio de las religiones comparadas) y de Friedrich Arnold Brockhaus (editor de las ConversationsLexikon y de la Encyplopedia Brockhaus).

Ahora bien, además de la influencia francesa, inglesa y alemana y pese a las palabras de Serrano sobre la tradición española, reconoce que «ya antes de ahora hase tributado en España honrosa acogida a obras enciclopédicas de ciencias elevadísimas» y entre estos textos cita el Diccionario razonado de legislación y jurisprudencia de Joaquín Escriche (1847, 3. ${ }^{a}$ ed.), el Diccionario filosófico de la religión del abate Nonnote (traducido al español por Joaquín María de Parada, Madrid, 1850), el Diccionario enciclopédico de la Teología católica de José Hernández Ardieta, el Dictionnaire d'économie politique de Guillaumin (París, 1852), el Dictionnaire des Lettres, BeauxArts, Sciences Morales et politiques de Bachelet (París, 1872), el Dictionnaire général des Sciences et théoriques apliqués de Jean Focillon y Aguntin Deschanel (París, 
1870), el Diccionario geográfico-estadístico-histórico de España y sus posesiones de Ultramar de Pascual Madoz (Madrid, 1845-1850), el Diccionario de la lengua castellana (1 $1^{\mathrm{a}}$ edición, 1869) de la Real Academia Española ${ }^{14} \mathrm{y}$ «otros varios [diccionarios] de Medicina, Farmacia, Artes, Industria, Navegación y Comercio» (p. IX).

Un cotejo preliminar del Diccionario universal con los escritos citados arroja interesantes datos que habrá que investigar en el futuro:

\begin{tabular}{|c|c|}
\hline DRAE-1869 & DICCIONARIO UNIVERSAL (1875) \\
\hline $\begin{array}{l}\text { ACOPIAR. a. Hacer acopio, o juntar en } \\
\text { cantidad alguna cosa. Dícese más común- } \\
\text { mente de los granos, provisiones, etc. }\end{array}$ & $\begin{array}{l}\text { Acopiar: v. a. Hacer acopio, o juntar en } \\
\text { cantidad alguna cosa.-Dícese más co- } \\
\text { múnmente de los granos, provisiones, etc. }\end{array}$ \\
\hline $\begin{array}{l}\text { AGRIO, IA. adj. Acido, acerbo al gusto \| } \\
\text { met. Aplícase .al camino, terreno o sitio } \\
\text { que es áspero o está lleno de peñascos y } \\
\text { breñas } \| \text { met. Acre, áspero, desabrido; } \\
\text { como genio AGRIO, respuesta AGRIA } \| \\
\text { En los metales, el que no es dócil, y que por } \\
\text { su aspereza no se deja labrar con facilidad } \| \\
\text { Pint. Lo que es de mal gusto en el colorido } \\
\text { y dibujo } \| \mathrm{m} \text {. El zumo ácido o acerbo de } \\
\text { algunas frutas. }\end{array}$ & $\begin{array}{l}\text { Agrio, ia: adj. Acido, acerbo al gusto. - } \\
\text { Met. Aplícase .al camino, terreno o sitio } \\
\text { que es áspero o está lleno de peñascos y } \\
\text { breñas._- Acre, áspero, desabrido; como } \\
\text { genio AGRIO, respuesta AGRIA.-En los } \\
\text { metales, el que no es dócil, y que por su } \\
\text { aspereza no se deja labrar con facilidad.- } \\
\text { Pint. Lo que es de mal gusto en el colorido } \\
\text { y dibujo.-S. m. El zumo ácido o acerbo de } \\
\text { algunas frutas.-Zool.Se llama así a un } \\
\text { género de insectos bracóceros [...]. }\end{array}$ \\
\hline $\begin{array}{l}\text { Feble: adj. Débil, flaco \| Llaman así los } \\
\text { plateros, monederos y lapidarios a lo que es } \\
\text { defectuoso en peso o ley \| La moneda fal- } \\
\text { ta.--met. ant. El flaco de una persona ó cosa. }\end{array}$ & $\begin{array}{l}\text { Feble: adj. ant. Débil, flaco._-Entre lapida- } \\
\text { rios, monederos y plateros, lo que es defectuo- } \\
\text { so en peso o ley.-S. m. L a moneda falsa.- } \\
\text { met. ant. El flaco de una persona o cosa. }\end{array}$ \\
\hline $\begin{array}{l}\text { Febrero. m. Segundo mes del año, que tiene } \\
28 \text { días, y el año bisiesto } 29 \text {. }\end{array}$ & $\begin{array}{l}\text { Febrero: s. m. Segundo mes del año civil, el } \\
\text { más corto de los doce, pues sólo cuenta } \\
\text { veintiocho días y en los años bisiestos } \\
\text { veintinueve. Aunque se indica el signo } \\
\text { zodiacal de Piscis como correspondiente a } \\
\text { Febrero, la mayor parte de este mes trascu- } \\
\text { rre mientras el Sol se halla todavía en Acua- } \\
\text { rio; hacia el dia } 20 \text { es cuando el Sol entra } \\
\text { verdaderamente en la constelación de Pis- } \\
\text { cis. En el mes de Febrero los días van cre- } \\
\text { ciendo, al monos para nosotros, porque en } \\
\text { unos puntos de la Tierra de crecen cuando } \\
\text { en otros crecen, así comopara unos pueblos } \\
\text { es invierno, cuandopara otros verano [...]. }\end{array}$ \\
\hline
\end{tabular}

${ }^{14}$ Nicolás Serrano afirma en la página VII del prólogo: «Lejos, pues, de formar coro con aquellos que claman contra la autoridad del Diccionario de la Lengua Castellana, calificándole de rémora autorizada a todo linaje de progresos en el lenguaje, nosotros le acatamos tan de buen grado, que creemos punto menos que verdad inconcusa, la de pecar en criminal arrogancia quien quiera que, profanando el código de la lengua, se atreva a legislar con derecho propio introduciendo peligrosas novedades. Obra humana como todas, ha menester reformas el Diccionario de una lengua; pero sean otorgados a la prudencia, al uso, al tiempo y al saber, los títulos que para sí reclame el espíritu innovador de la época». 
RÁFAGA. f. El movimiento violento del aire que hiere repentinamente y que por lo común tiene poca duración. $\|$ Cualquiera nubecilla que aparece de poco cuerpo o densidad, especialmente cuando hay o quiere haber mutación de tiempo. \| Golpe de luz vivo e instantáneo.

RATEAR. a. Disminuir o rebajar a proporción o prorata. || Distribuir, repartir proporcionadamente. || Hurtar cosas pequeñas con destreza y sutileza. $\| \mathrm{n}$. Andar arrastrando con el cuerpo pegado a la tierra.

RATIFICACIÓN. f. La acción y efecto de ratificar o ratificarse.
Ráfaga: s. f. Cada uno de los movimientos o sacudidas violentas del aire que hiere repentinamente, y que suele ser de corta duración.- Cualquiera nubecilla ligera, que aparece de poco cuerpo o densidad, especialmente cuando hay o se prepara o se anuncia cambio atmosférico, variación o mutación de tiempo.- Golpe de luz vívido e instantáneo. Se usa también bastante en el sentido metafórico.

Ratear: v. a. Disminuir o rebajar a proporción o prorata. - Distribuir, repartir proporcionalmente. - Hurtar cosas pequeñas con destreza y sutileza. Se usa también como recíproco. - v. n. Andar arrastrando con el cuerpo pegado a la tierra.

Ratificación. s. f. La acción y efecto de ratificar o ratificarse. Legisl. Confirmación, corroboración, aprobación definitiva de lo que hemos dicho o hecho, o de lo que otro ha hecho en nuestro nombre. Puede hacerse la ratificación o bien expresamente con términos positivos o bien tácitamente con hechos. La ratificación tiene efecto retroactivo, de modo que sube o se retrotrae al día del acto o contrato; mas para que así sea es preciso que el acto o contrato no haya tenido nulidad esencial en su principio [...].
DICCIONARIO RAZONADO DE LEGISLACIÓN Y JURISPRUDENCIA, JOAQUÍN ESCRICHE (1847)

ABACERÍAS. Las tiendas o puestos públicos donde se vende por menor aceite, vinagre, pescado, legumbres secas y otros artículos de ordinario consumo.

No siempre ha podido cualquiera establecer libremente ABACERÍAS. Hubo un tiempo en que algunos se arrogaban este privilegio, y no permitían su ejercicio, sino a los sujetos a quienes lo daban en arriendo; mas don Fernando y doña Isabel, en pragm. de 4 de Diciembre de 1492, y D. Carlos y doña Juana, en 1532 (ley 1 , tít . XXI, lib. 6, Nov. Recop.), prohibieron a todas las personas de cualquier estado y posición, preeminencia y dignidad el poner tales estancos o vedamientos en sus villas, lugares, tierras u otras partes, bajo las penas en que caen por las leyes los que piden y llevan nuevas imposiciones, por ser contra-

\section{DICCIONARIO UNIVERSAL (1875)}

Abacerías: s. f. Las tiendas o puestos públicos donde se vende por menor aceite, vinagre, pescado, legumbres secas y otros artículos de ordinario consumo.

No siempre ha podido cualquiera establecer libremente ABACERÍAS. Hubo un tiempo en que algunos se arrogaban este privilegio, y no permitían su ejercicio, sino a los sujetos a quienes lo daban en arriendo; mas don Fernando y doña Isabel, en pragm. de 4 de Diciembre de 1492, y D. Carlos y doña Juana, en 1532 (ley 1, tít . XXI, lib. VI, Nov. Recop.), prohibieron a todas las personas de cualquier estado y posición, preeminencia y dignidad el poner tales estan$\cos$ o vedamientos en sus villas, lugares, tierras u otras partes, bajo las penas en que caen por las leyes los que piden y llevan 
rias a derecho y conciencia, y en gran daño de los súbditos y vecinos [...].

Con el fin aparente de evitar estos males imaginarios, tomaron a su cargo los ayuntamientos la tutela de sus convecinos, y o bien administraron por cuenta del público el surtido de los artículos de primera necesidad o bien buscaron asentistas exclusivos que se obligasen a procurarlos y venderlos a tales o tales precios concertados [...].

ACOTAMIENTO. La acción y efecto de poner cotos o mojones y cercar las heredades.

En principio, todo propietario puede acotar, esto es, cercar o cerrar sus fincas rurales en virtud del derecho de propiedad, porque la conservación y el goce pacífico de sus frutos, que no puede lograrse sin el acotamiento, son efectivamente atributos del dominio. El ejercicio de esta facultad de los propietarios es además utilísimo al Estado: $1 .^{\circ}$, porque mediante los cerramientos se puede obtener la multiplicación que tanto se desea de los árboles y abundancia de leñas y maderas para el carboneo, para la construcción de edificios y para la marina; $2 .^{\circ}$, porque así se perfecciona el cultivo y se saca mayor cantidad de productos en menos cantidad de tierra, de modo que la riqueza nacional, que no es más que la suma de las riquezas individuales, debe adquirir un aumento extraordinario; $3 .^{\circ}$, porque es consiguiente que crezca y se multiplique la población, que se disminuya el número de proletarios, que los campos se llenen de habitantes, que se alcen en todas partes edificios agradables y se afiance la seguridad de los caminos.

Sin embargo de todo, una costumbre bárbara, nacida en tiempos bárbaros y sólo digna de ellos, como dice el Sr. Jovellanos, introdujo la bárbara y vergonzosa prohibición de cerrar las tierras, y menoscabando la propiedad individual en su misma esencia, opuso al cultivo uno de los estorbos que más poderosamente ha detenido su progreso. Esta costumbre hubo de tener su origen en aquellos tiempos de guerras intestinas en que estando espuestos los campos a frecuentes devastaciones y siendo inútil cerrarlos, se contentaban los dueños o colonos con sembrar y alzar el fruto, dejándolos nuevas imposiciones, por ser contrarias a derecho y conciencia, y en gran daño de los súbditos y vecinos.

Más tarde tomaron a su cargo los ayuntamientos la tutela de sus vecinos, y o bien administraron por cuenta del público el surtido de los artículos de primera necesidad, o bien buscaron asentistas exclusivos que se obligasen a procurarlos y venderlos a tales o tales precios concertados [...].

Acotamiento: s. m. La acción y efecto de poner cotos o mojones y cercar las heredades.

En principio, todo propietario puede acotar, esto es, cercar o cerrar sus fincas rurales en virtud del derecho de propiedad, porque la conservación y el goce pacífico de sus frutos, que no puede lograrse sin el ACOTAMIENTO, son efectivamente atributos del dominio. El ejercicio de esta facultad de los propietarios es además utilísimo al Estado: $1 .^{\circ}$, porque mediante los cerramientos se puede obtener la multiplicación que tanto se desea de los árboles y abundancia de leñas y maderas para el carboneo, para la construcción de edificios y para la marina; $2 .^{\circ}$, porque así se perfecciona el cultivo y se saca mayor cantidad de productos en menos cantidad de tierra, de modo que la riqueza nacional, que no es más que la suma de las riquezas individuales, debe adquirir un aumento extraordinario; $3 .^{\circ}$, porque es consiguiente que crezca y se multiplique la población, que se disminuya el número de proletarios, que los campos se llenen de habitantes, que se alcen en todas partes edificios agradables y se afiance la seguridad de los caminos.

Sin embargo de todo, una costumbre grosera, nacida en tiempos bárbaros y sólo digna de ellos, como dice el Sr. Jovellanos, introdujo la bárbara y vergonzosa prohibición de cerrar las tierras, y menoscabando la propiedad individual en su misma esencia, opuso al cultivo uno de los estorbos que más poderosamente ha detenido su progreso. Esta costumbre hubo de tener su origen en aquellos tiempos de guerras intestinas en que estando expuestos los campos a frecuentes devastaciones y siendo inútil cerrarlos, se contentaban los dueños o colonos con sembrar y alzar el fruto, dejándolos 


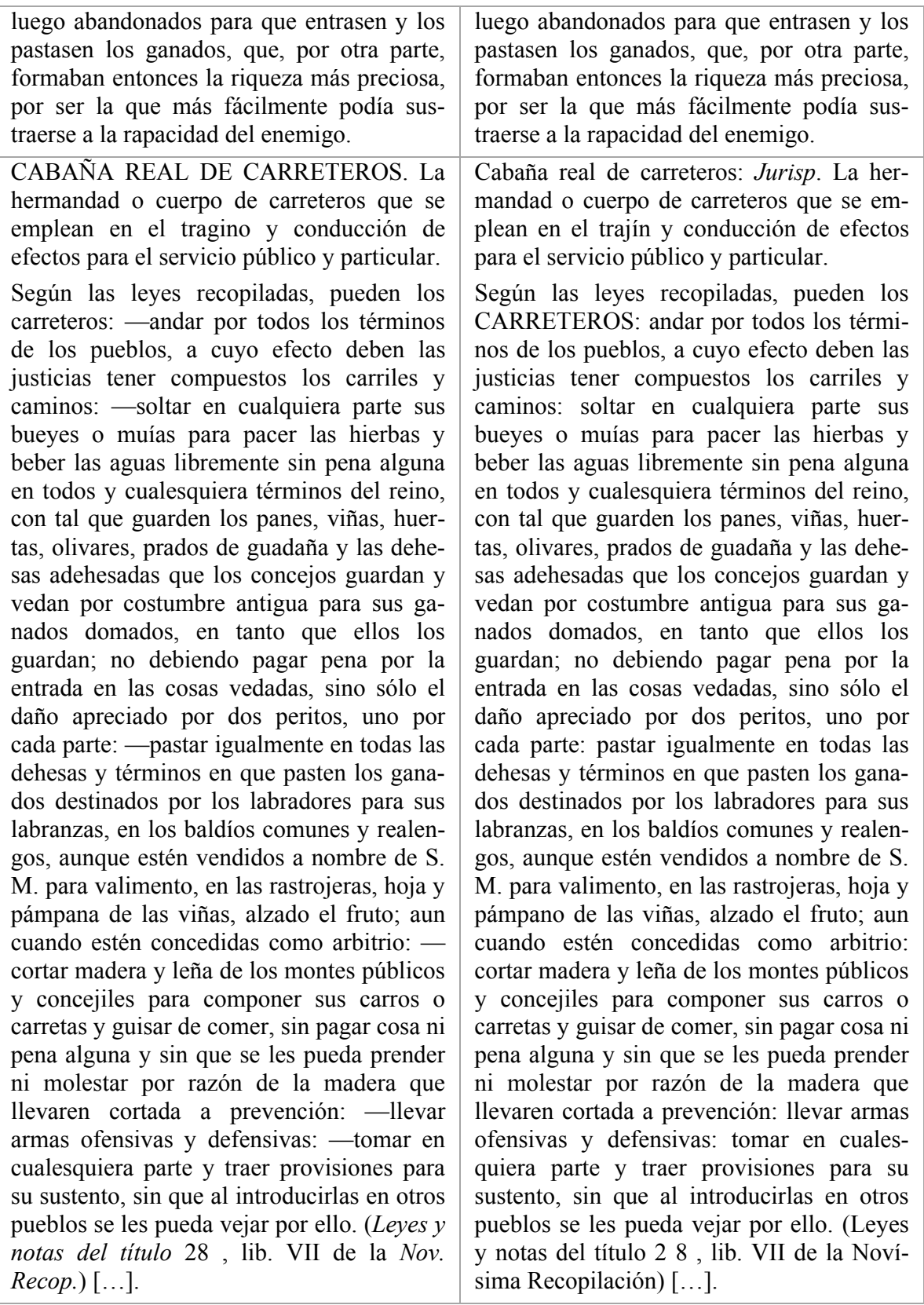

Estos pocos ejemplos muestran que el Diccionario universal se sirvió del DRAE para la redacción de la parte lingüística del artículo lexicográfico y de otras muchas fuentes para la parte enciclopédica, y que Nicolás Serrano, como director, no siempre fue igual de cuidadoso y respetuoso con los textos que servían de modelo. 
Por otro lado, es necesario recordar que el Diccionario universal también fue utilizado con posterioridad en otros repertorios, así, Enrique de Leguina en su Glosario de voces de armería (Madrid, 1912) ${ }^{15}$ lo cita entre sus fuentes y lo utiliza en la redacción de algunos artículos

Gocete.- Esta palabra es una de las que mayor confusión han ocasionado a los escritores españoles. Desde el Diccionario de la Lengua, suponiendo que era una pieza de la armadura destinada a cubrir la cabeza, error admitido en el Diccionario universal publicado por Serrano, en el militar, redactado por Hevia, en el etimológico de Barcia, y en el enclicop. hisp. americano, hasta los que, como Bescherelle, afirman que aquella voz solo debe aplicarse a una pequeña pieza triangular que resguardaba la parte inferior del brazo, han sido varias y muy opuestas las interpretaciones admitidas, originadas en haber sido designadas cosas muy distintas con el solo nombre de gocete.

Gocete de lanza. «Rodete de cuero o hierro que hay clavado en la manija de la lanza». Serrano.-Diccionario universal, 1881.

Del mismo modo, el Diccionario universal es, como ha demostrado Pardo Herrero (2012), «una fuente visible [...] cuyo uso se reconoce en la lista de obras que en encuentran en el documento del Fondo Montaner y Simón» (pp. 401) del Diccionario Enciclopédico Hispano-Americano de Literatura, Ciencias y Artes (Barcelona, 18871889) de la editorial Montaner y Simón. La investigación realizada por la doctora Pardo Herrero pone de manifiesto que «la utilización de esta obra se confirma solamente en el inicio del DEHA. El uso realizado casi exclusivamente al comienzo no hace de la obra, sin embargo, una fuente secundaria, pero sí es un dato a tener en cuenta para reflexionar sobre por qué deja de utilizarse. La razón, en el contexto editorial podría ser que simplemente Benot la usara y Pagès decidiera dejar de hacerlo por no satisfacerle el contenido. Pero también podría estar relacionada con el conflicto judicial por los derechos sobre el Diccionario universal que Montaner y Simón peleaba a través de Pi y Margall con Astort editores. Ese conflicto podría haber dado paso a que el $D E H A$ dejara de hacer uso de la obra de Astort por orden de esa casa editorial, o bien como un tipo de "castigo" por los problemas entre ellos» (2012: 401).

\section{A MODO DE CONCLUSIÓN}

Pese a que, en palabras del Conde de la Viñaza (1893: 1601), el «provecho que del Diccionario universal puede sacarse para la filología propiamente dicha es menor de lo que pudiera prometerse quien mirase solamente a la mole o apariencia exterior de la obra, como quiera que, nula en la parte de etimología de las palabras, y muy escasa en las acepciones de estas y respecto de las definiciones, se reduce en general a copiar o

\footnotetext{
${ }^{15}$ En palabras de Pérez de Guzmán y Gallo, «su obra monumental el Glosario de voces de Armería, cuya utilidad es indiscutible, pues ha de prestar en lo sucesivo auxilios eminentes, en cada palabra y en las autoridades que el autor cita para definir el empleo que de ellas se hizo en los pasados siglos, a los que en otro campo de acción se consagran a la ilustración viva y minuciosa de la narración de los sucesos al bosquejo biográfico de los personajes y a la descripción de los usos y costumbres en la esfera de cada clase social de los siglos a que se remontan» $(1913,245-246)$.
} 
traducir lo que se halla escrito en otros libros»; y pese a que faltan todavía muchos aspectos por analizar (la marcación, el tratamiento dado al léxico de la ciencia y de la técnica, las fuentes, la información metalexicográfica contenida en el prólogo y dentro del Diccionario, la información lingüística o las definiciones lexicográficas subjetivas, por poner solo algunos ejemplos), el Diccionario universal de Serrano forma parte de la historia de la Lexicografía no académica del siglo XIX, y constituye, a pesar de los parecidos con otros diccionarios enciclopédicos decimonónicos, como también señala el Conde de la Viñaza (1893: 1601), «la empresa más vasta sin duda de cuantas se habían acometido hasta su tiempo en España [...]. Con todo merece consultarse, pues a vuelta del cúmulo inmenso de noticias de todos géneros que atesora, contiene muchas que pueden ser útiles en gran manera al filólogo o gramático».

\section{REFERENCIAS BIBLIOGRÁFICAS}

Alvar EzQuerRa, Manuel (1980): «¿Qué es un Diccionario?», Lingüistica Española Actual, 11, 1, pp. 103-118.

(1993): «El diccionario de la Academia en sus prólogos», en Lexicografía descriptiva, Barcelona, Biblograf, pp. 215-239.

(2010: «Un siglo de lexicografía bilingüe español-italiano: el XIX», en M. C. Ayala Castro y A. M. Medina Guerra, ed. y coord., Diversidad lingüistica y diccionario, Málaga, Universidad de Málaga, pp. 43-118.

ÁlvareZ DE MiRANDA, Pedro (2000): «La lexicografía académica de los siglos XVIII y XIX», en I. Ahumada, ed., Cinco siglos de lexicografia del español. IV Seminario de Lexicografía Hispánica, Jaén, Universidad de Jaén, pp. 35-61.

- (2007): «Panorama de la lexicografía española en el siglo XIX», en J. Dorta, C. Corrales y D. Corbella, eds., Historiografía de la lingüística en el ámbito hispánico: fundamentos epistemológicos y metodológicos, Madrid, Arco/Libros, pp. 329-356.

ANAYA REVUELTA, Inmaculada (2000a): «Los diccionarios enciclopédicos del español actual». Revista de Lexicografia, 6, pp. 7-36.

(2000b): «Sobre el carácter enciclopédico de los diccionarios del español», Boletín de la Real Academia Española, LXXX, pp. 177-207

AngladA, Emilia y María BARgalló (1992): «Principios de lexicografía moderna en diccionarios del siglo XIX», en M. Ariza et al., Actas del II Congreso Internacional de Historia de la Lengua Española, Madrid, Arco/Libros, I, pp. 955-962.

ARCE, Ángeles (1988): «Principales gramáticas y diccionarios bilingües en la España del XIX», en El siglo XIX italiano, Salamanca, Universidad de Salamanca, pp. 7-15.

AZORÍN FERNÁNDEZ, Dolores (1994-1995): «De la teoría a la práctica lexicográfica: El nuevo diccionario de la lengua castellana de Vicente Salvá», Estudios de Lingüistica, 10, pp. 9-20.

(2000a): «El diccionario de la Real Academia Española y su evolución interna (siglos XVIII-XIX-XX)», en Los diccionarios del español en su perspectiva histórica, Alicante, Universidad de Alicante, pp. 273-302. 
(2000b): «La lexicografía monolingüe del español en el siglo XIX: desarrollos extra-académicos)», en Los diccionarios del español en su perspectiva histórica, Alicante, Universidad de Alicante, pp. 229-256.

BÉJOINT, Henri (2004 [1994]): Modern Lexicography. An Introduction, Oxford-Nueva York, Oxford University Press.

BergenHOlTZ, Henning y Sven TARP (2002): «Die moderne lexikographische Funktionslehre, Diskussionsbeitrag zu neuen und alten Paradigmen, die Wörterbücher als Gebrauchsgegenstände verstehen», Lexicographica, 18, pp. 253-263

BRUÑa CuEVAS, Manuel (2008): «Las producción lexicográfica con el español y el francés durante los siglos XVI a XIX», Philologia Hispalensis, 22, pp. 37-111.

Bueno Morales, Ana M. ${ }^{a}$ (1995): La lexicografia no académica monolingüe del siglo XIX, Málaga, Universidad de Málaga (tesis doctoral inédita).

CAmpos Souto, Mar y José Ignacio PÉRez PASCuAL (2003): «El diccionario y otros productos lexicográficos», en Antonia M. ${ }^{a}$ Medina Guerra, coord., Lexicografía española, Barcelona, Ariel, pp. 53-78.

CAZORLA VIVAS, M. ${ }^{\mathrm{a}}$ del Carmen (2004): Lexicografia bilingüe de los siglos XVIII y XIX con el español y el francés, Madrid, Universidad Complutense.

- (2010): «Panorama de la lexicografía bilingüe y plurilingüe del español a comienzos del siglo XIX», en F. San Vicente, dir., Textos fundamentales de la lexicografía italoespañola (1805-1916), Monza, Polimetrica International Scientific Publisher, pp. 2756.

FernándeZ-SeVILla, Julio (1974): Problemas de Lexicografia actual, Bogotá, Instituto Caro y Cuervo.

FILLMORE, Charles (2008a): «An Alternative to checklist theories of meaning», en P. Hanks, ed., Lexicology, Londres-Nueva York, Routledge, IV, pp. 219-226.

- (2008b): «Towards a Frame-based Lexicon. The semantic of Risk and its neighbors», en P. Hanks, ed., Lexicology, Londres-Nueva York, Routledge, IV, pp. 227-253.

- et alii (2003): «Background to Framenet», International Journal of Lexicography, 16,3 , pp. $235-250$.

Fontenelle, Thierry, ed. (2008): Practical Lexicography, Oxford, Oxford University Press.

FoRGAS, Esther, coord. (1996): Léxico y diccionarios, Tarragona: Universitat Rovira i Virgili.

GARCÍA ARANDA, M. ${ }^{a}$ Ángeles (2012): «Lexicografía», en Alfonso Zamorano, ed. y coord., Reflexión lingüistica y lengua en la España del siglo XIX. Marcos, panoramas y nuevas aportaciones, München, Lincom, pp. 117-138.

GARCÍA PlATERO, Juan Manuel (2003): «La lexicografía no académica en los siglos XVIII y XIX», », en Antonia M. ${ }^{a}$ Medina Guerra, coord., Lexicografia española, Barcelona, Ariel, pp. 263-280.

GERAERTS, D. (2003): «Meaning and Definition», en P. Van Sterkenburg, ed., A Practical Guide to Lexicography, Amsterdam-Philadelphia, John Benjamins, pp. 83-93.

GUTIÉRREZ CUADRADO, Juan (1996): «Enciclopedia y diccionario», en Esther Forgas, coord., Léxico y diccionario, Tarragona, Universidad Rovira i Virgili, pp. 133-159.

HAENSCH, Günther, Lothar WOLF, Stefan ETTINGER y Reinhold WeRNER (1982): La Lexicografía. De la Lingüistica teórica a la Lexicografia práctica, Madrid, Gredos.

HAENSCH, Günther y Carlos OMEÑACA (2004): Los diccionarios del español en el siglo $X X I$, Salamanca, Universidad de Salamanca. 
HANKS, Patrick, ed. (2008): Lexicology, Londres-Nueva York, Routledge.

Hartmann, R. R. K., ed. (2003): Lexicography. Critical Concepts, Londres-Nueva York, Routledge.

HERNÁNDEZ HERNÁNDEZ, Humberto (1994):. «Diccionarios enciclopédicos», en H. Hernández, coord., Aspectos de Lexicografía contemporánea, Barcelona, Biblograf, pp. 61-71.

(1997): «Del Diccionario a la Enciclopedia: los diccionarios enciclopédicos», en M. Almeida y J. Dorta, eds., Homenaje al Profesor Ramón Trujillo, Santa Cruz de Tenerife, Montesinos, pp. 155-164.

IBARRETXE-ANTUÑANO, Iraide y Javier VALENZUELA (2012): Lingüística Cognitiva, Barcelona, Anthropos.

LABOV, William (2008 [1973]): «The Boundaries of Words and their Meanings», en P. Hanks, ed., Lexicology, Londres-Nueva York, Routledge, IV, pp. 377-407

LARA, Luis Fernando (1989): «Dictionnaire de langue, encyclopédie et diccionaire encyclopédique: le sens de leur distinction», en F. J. Hausmann et al., eds., Wörterbücher. Dictionaries. Dictionnaires. Ein internacionales Handbuch zur Lexicographie. An International Encyclopedia of Lexicography. Encyclopédie internationale de lexicographie, Berlín, Walter de Gruyter, I, pp. 280-287.

(1990): Dimensiones de la lexicografia: a propósito del Diccionario del español de México, México, El Colegio de México.

MARELlo, Carla (1989): Dizionari bilingui con schede sui dizionari italini per francese, inglese, spagnolo, tudesco, Pavia, Librería Parnaso.

MARTínez EGIDO, José Joaquín (2008): «Origen y desarrollo positivo de la lexicografía bilingüe español-italiano (siglos XV-XIX)», Philologia Hispalenses, 22, pp. 213-258.

MARTÍNEZ MARÍN, Juan (2000): «La lexicografía monolingüe del español en el siglo XIX: la corriente no académica en I. Ahumada, ed., Cinco siglos de lexicografía del español. IV Seminario de Lexicografia Hispánica, Jaén, Universidad de Jaén, pp. 63-77.

PARdo Herrero, Pilar (2012): El Diccionario Enciclopédico Hispano-Americano de Montaner y Simón: a propósito del léxico de la ciencia y de la técnica, Barcelona, Universitat Autònoma de Barcelona [http://hdl.handle.net/10803/96707]

PÉREZ DE GUZMÁN Y GALlO, Juan (1913): «Glosario de voces de armería por D. Enrique de Leguina, barón de la Vega de Hoz», Boletín de la Real Academia de la Historia, 62, pp. 242-249.

Porto DAPenA, José-Álvaro (2002): Manual de técnica lexicográfica, Madrid, Arco/Libros.

REY, Alain (1988): Enciclopedias y diccionarios, México, FCE.

RUHSTALlER, Stefan (2003): «Las obras lexicográficas de la Academia», en Antonia M. ${ }^{\text {a }}$ Medina Guerra, coord., Lexicografía española, Barcelona, Ariel, pp. 235-262.

SAN ViCENTE, Félix (2010): Textos fundamentales de la lexicografía italoespañola (18051916), Monza, Polimetrica International Scientific Publisher.

SCHIFFrin, Deborah, ed. (1984): Meaning, Form \& Use in Application Context: Linguistics, Washington, Georgetown University Press.

SECO, Manuel (2003 [1987]): «El nacimiento de la lexicografía moderna no académica», en Estudios de lexicografía española. Segunda edición aumentada, Madrid, Gredos, pp. 259-284. 
(2003 [1987]): «Un lexicógrafo romántico: Ramón Joaquín Domínguez», en Estudios de lexicografía española. Segunda edición aumentada, Madrid, Gredos, pp. 285299.

(2003 [1987]): «La definición lexicográfica subjetiva: el Diccionario de Domínguez», en Estudios de lexicografía española. Segunda edición aumentada, Madrid, Gredos, pp. 300-314.

SOLER I BOU, Joan (2006): Definició lexicogràfica i estructura del diccionari, Barcelona, Intitut d'Estudis Catalans.

VAn Sterkenburg, Piet, ed. (2003): A Practical Guide to Lexicography, AmsterdamPhiladelphia, John Benjamins.

VIÑAZA, Conde de la (1893): Biblioteca histórica de la Filología castellana, Madrid, Imprenta y Fundición de Manuel Tello. 